\title{
OS JOGOS ELETRÔNICOS NA ERA DO ALUNO VIRTUAL: BRINCAR E APRENDER
}

\author{
Leovigildo Samuel Santana
}

Docente da Faculdade de Presidente Venceslau - FAPREV/ UNIESP. E-mail: Santana.leosamuel@gmail.comás

\begin{abstract}
RESUMO
Com o uso dos recursos tecnológicos computacionais na Educação, possibilita-se uma aprendizagem de forma motivadora e moderna. Dentre essas tecnologias destacamos o jogo eletrônico, que pode contribuir para uma melhor aprendizagem, considerando que os jovens estão ficando mais tempo à frente de um computador ou consoles de videogames. Em nossa pesquisa estudamos especificamente a utilização do jogo eletrônico CALL OF DUTY, avaliando a influência do mesmo na aprendizagem dos alunos referente ao período da Segunda Guerra Mundial. $O$ trabalho de pesquisa foi realizado numa escola da rede pública estadual localizada na região central da cidade de Presidente Prudente. Utilizamos como técnica de pesquisa a aplicação de um questionário exploratório aos sujeitos com um conjunto de questões abertas. Concluímos que foi possível com o jogo praticar uma aprendizagem cooperativa entre os sujeitos, visto que a cada ação, etapa, os mesmos trocavam informações para avançar às etapas seguintes.
\end{abstract}

Palavras-chave: Educação. Jogos Eletrônicos. Tecnologia Educacional. Práticas Educativas.

\section{INTRODUÇÃO E OBJETIVOS}

Os jogos eletrônicos mesmo que ainda sejam alvos de resistência por parte de pais, professores e especialistas quanto aos resultados que os mesmos podem oferecer, argumentando-se que os jogos deixam os jovens por muito tempo à frente do computador ou console de videogame, isolando-se e tornando-se menos sociáveis, porém acabam por ficar viciados por eles, é importante ressaltar que estamos vivendo uma nova época. Os alunos que frequentam as escolas hoje são completamente diferentes dos demais, considerando que atualmente o acesso às tecnologias é bem superior ao das duas últimas décadas, tendo como referência a internet ${ }^{1}$.

O uso de jogos eletrônicos na educação pode contribuir para uma melhoria no processo ensino - aprendizagem, considerando que, cada vez mais, os jovens buscam ficar mais tempo à frente de um computador ou console de videogame em seu momento de lazer (e ao mesmo tempo, de aprendizagem). Levar esses jogos à educação significará o uso de mais uma ferramenta à disposição do professor, que poderá explorá-la das mais diversas formas e conteúdos.

\footnotetext{
${ }^{1} \mathrm{O}$ ano de 1995 foi um marco. Os ministérios das Comunicações e da Ciência e Tecnologia criaram, por portaria, a figura do provedor de acesso privado à Internet e liberaram a operação comercial no Brasil. No ano seguinte, muitos provedores começaram a vender assinaturas de acesso à rede. Fonte: <http://tecnologia.terra.com.br/internet10anos/interna/0,OI541825-El5026,00.html> Acesso em: 07/06/13.
} 
A justificativa é que as crianças e jovens formam a primeira geração mergulhada integralmente na tecnologia. Os videogames apresentam uma série interminável de desafios ao jogador - para alcançar os objetivos do jogo, ele é obrigado a todo instante a avaliar e organizar as informações disponíveis e priorizá-las, e baseado nelas, tomar decisões estratégicas de curto ou longo prazo. Os jogos permitem aos alunos correlacionar fatos e a não vê-los isoladamente. No entendimento de Alves (2005, p. 17):

O uso de jogos eletrônicos poderá levar o aluno a ter acesso às diversas áreas do conhecimento, facilitando o seu aprendizado e contribuindo para o desenvolvimento social, cognitivo e afetivo dos sujeitos, podendo ser denominados "tecnologias intelectuais".

Para muitos, jogar é tão somente uma brincadeira, um momento de recreação. Mas jogar pode ser também um instrumento interessante de aprendizagem, pois o "jogo é sinônimo de atividade lúdica" (MENDES, 2006, p. 18).

A educação tem quer vista como algo que dê prazer. Tem que se aprender "brincando". Não é o brincar por brincar, mas é o brincar para aprender.

Escolhemos o jogo eletrônico CALL OF DUTY, por se tratar de um jogo que retrata a Segunda Guerra Mundial, um tema ainda muito discutido na atualidade devido às muitas mortes ocorridas entre os países do eixo e os aliados e os resultados decorrentes de seu término, como a formação de um mundo dividido em dois blocos de influência e de muita rivalidade. Outro motivo para a escolha desse game é o de ele ser considerado um dos melhores entre àqueles que narram a Segunda Guerra Mundial.

O conhecimento está em constante transformação, se renovando e se reconstruindo. Para tanto, Bettega (2004, p. 11) ressalta que "o computador deve permitir criar ambientes de aprendizagem que façam surgir novas formas de pensar e de aprender".

Arruda (2004, p. 82), lembra que o "aprender com as mídias traz novos significados ao nosso cérebro, uma nova leitura do mundo".

A geração virtual ${ }^{2}$ tem desenvolvido novas habilidades e competências que lhe permite desencadear uma série de ações simultâneas sem, contudo, perder o foco da ação principal. Ela gosta de zapear, seja pela TV, passeando pelos canais via controle remoto ou mesmo pela internet, navegando por várias páginas ao mesmo tempo e ainda ouvir músicas e conversar.

\footnotetext{
${ }^{2}$ Geração cercada pelas mídias digitais. Vêem o computador como extensão natural de suas vidas e são mais bem informados do que qualquer geração anterior. Fonte: <http://www.istoe.com.br/reportagens/34355_GERACAO+VIRTUAL> Acesso em: 07/06/13; Geração Digital; Geração @ (MOITA, 2007); Geração net (ALVES, 2005); Screenagers (RUSHKOFF (1999) apud ALVES, 2005).
} 
Jogando, esses jovens estão desenvolvendo uma série de competências e habilidades, como as da escrita e a capacidade de desenhar com ambas as mãos, além de uma habilidade sensorial e espacial, desenvolvendo assim, segundo Mendes (2006, p. 26), "as técnicas intelectuais (ler os manuais dos jogos; memorizar as dificuldades dos jogos; diferenciar em qual momento fazer o personagem do jogo correr rápido ou lento, saltar, parar etc.)".

Nesse contexto de ensinar muitas coisas por meio do jogo propusemos os seguintes objetivos:

1. Avaliar os conhecimentos dos alunos sobre o período da Segunda Guerra Mundial, estabelecendo relação entre o aluno, o tema Segunda Guerra mundial e o jogo eletrônico CALL OF DUTY para que se estabeleçam condições de aprendizagem apropriando-se dos recursos midiáticos e integrando-os a um contexto pedagógico que venha ao encontro aos interesses dos alunos, contribuindo para uma melhoria na qualidade de ensino.

2. Estimular o desenvolvimento de uma aprendizagem cooperativa entre os sujeitos envolvidos

3. Promover a relação ensino-aprendizagem através do uso de jogos eletrônicos como prática educativa.

4. Estimular os professores a buscarem novas estratégias de ensino a partir das Tecnologias de Informação e Comunicação

\section{METODOLOGIA}

$\mathrm{Na}$ atual sociedade aprendemos a conviver diariamente com a tecnologia em seus mais diversos segmentos e ambientes.

Os jogos propiciam envolvimento entre os sujeitos e o conhecimento ocorre por meio de descobertas e a interação entre os diversos meios de aprendizagem.

O trabalho desenvolvido buscou estudar como os jogos eletrônicos podem estimular a aprendizagem, sendo apropriados pelo profissional docente no desenvolvimento do processo ensino-aprendizagem através do uso de novas tecnologias.

Partimos rumo a uma abordagem qualitativa, sem, contudo, desconsiderar a abordagem quantitativa, também presente em nosso trabalho. As categorias quantitativas e qualitativas embora opostas são inseparáveis no processo de produção do conhecimento (GAMBOA, 1995, p. 108). 
Para nós, interessava mais o processo e menos os resultados, visto que não buscamos apenas quantificar e medir as respostas e desempenhos dos sujeitos. Levamos em conta que o importante estava principalmente na análise qualitativa que os jogos eletrônicos propiciariam à aprendizagem como ferramenta pedagógica a serviço do profissional docente e se os mesmos serviriam para o desenvolvimento de uma aprendizagem cooperativa.

Nosso trabalho, que envolveu perguntas e observações reforça a abordagem qualitativa, considerando que estivemos em todos os momentos próximos dos sujeitos, principal objeto desse tipo de abordagem.

Aplicamos aos alunos um conjunto de questões abertas sobre o período da Segunda Guerra Mundial com a proposta de saber o que os mesmos conheciam sobre o período. Nessa atividade as questões foram elaboradas levando em consideração o público alvo.

Os alunos foram organizados em duplas, não havendo qualquer tipo de intervenção por parte do aplicador do jogo, com o propósito de observar as atitudes dos alunos frente ao computador na relação erro e acerto e o relacionamento entre o grupo envolvido.

Outra preocupação para o desenvolvimento da pesquisa foi a de que indiretamente estaria desenvolvendo o estimulo ao trabalho cooperativo a partir da aplicação do jogo. Essa proposta propicia integração entre os sujeitos e desenvolve não apenas a aprendizagem, mas também a sociabilidade entre os mesmos.

Neste trabalho de pesquisa desenvolveu-se num período de três meses, dividido em quatro fases. Nesse período aplicamos um questionário exploratório aos sujeitos buscando analisar a relação entre eles e os jogos eletrônicos na primeira fase. Na segunda e quarta fases, aplicamos um questionário com questões sobre a Segunda Guerra Mundial e o jogo eletrônico CALL OF DUTY na terceira fase.

Para as atividades com o jogo CALL OF DUTY foi utilizada a Sala Ambiente de Informática SAl, equipada com doze computadores em rede.

\section{O jogo eletrônico CALL OF DUTY}

O período da Segunda Guerra Mundial vem sendo explorado em vários jogos, o que demonstra a importância desse acontecimento, que mesmo passado mais de meio século ainda é analisado sob vários ângulos, sendo um deles os jogos eletrônicos.

COD, como também é chamado, é um jogo de ação em primeira pessoa com a opção Multiplayer, podendo ser jogado em rede ou pela internet. O jogo tem como tema o período 
correspondente ao da Segunda Guerra Mundial, de 1939 a 1945, sendo considerado o conflito mais importante do Século XX, ainda muito discutido na atualidade em virtude das suas causas e consequências. Após a Segunda Guerra Mundial o mundo ficou dividido em dois grandes blocos, por dois sistemas socioeconômicos, capitalista e socialista, de um lado os Estados Unidos da América e de outro, a União das Repúblicas Socialistas Soviéticas. Tivemos nesse período pós guerra intensa corrida aeroespacial e armamentista. A Guerra Fria, como ficou denominado esse período, não se manifestou apenas no campo político, mas também na cultura e no esporte.

A história do jogo ocorre em vinte e quatro missões realizadas em quatro campanhas, ambientadas em 8 países e envolvendo soldados americanos, britânicos e russos. 0 jogo procura reproduzir a história da guerra em um cenário que busca retratar com fidelidade os lugares que serviram como palco do conflito no continente europeu em batalhas épicas como a batalha de Stalingrado, na Rússia, a Batalha de Berlim e desembarque na Normandia, que ficou conhecido como o do Dia D.

O jogo possui movimentos e táticas reais, onde a personalidade e treinamento de cada soldado são revelados no campo de batalha.

Logo ao iniciar o jogador recebe a missão de treinamento a ser cumprida Essa fase é importante para que o jogador possa receber outras missões e continuar a jogar. Seguir a orientação da bússola é um ponto a ser observado. Isso pode garantir ao jogador sucesso na sua missão.

Passado a fase de treinamento, o jogador torna-se apto a receber a sua primeira missão real de combate.

O jogo termina com a conquista de Berlim por tropas russas que hasteiam a bandeira soviética na conquista final da Reichstag.

\section{RESULTADOS}

O trabalho partiu do interesse que os jovens têm sobre os jogos eletrônicos. Essa avidez é que norteou a pesquisa sobre a relação jogos eletrônicos e educação no desenvolvimento de um novo ambiente de aprendizagem, como escreve Alves (2005, p. 230):

Outra aprendizagem importante relaciona-se à compreensão dos jogos como espaços de aprendizagem que devem ser explorados principalmente nos ambientes escolares, já que possibilitam a construção de conceitos vinculados aos aspectos sociais, cognitivos, afetivos e culturais. 
A grande dúvida era se os jogos eletrônicos, área de imersão dos jovens propiciaria condições de subsidiar os professores em suas aulas, já que os mesmos, em sua maioria, ainda relutam em utilizar as Salas Ambientes de Informática - SAl e se os jogos constituiriam em novos ambientes de aprendizagem, contribuindo para uma relação de cooperativismo entre os sujeitos e permitindo que sejam agentes ativos na produção do conhecimento.

Algumas perguntas que contribuíram para alcançar os objetivos propostos foram:

1. Os jogos eletrônicos possibilitam criar novos ambientes de aprendizagem?

2. Que relações os jovens estabelecem entre os jogos eletrônicos e a aprendizagem?

3. É possível estabelecer um modelo de aprendizagem cooperativa a partir dos jogos eletrônicos?

4. Os jogos eletrônicos contribuem para uma melhor socialização dos sujeitos?

Essas indagações é que subsidiaram todo o processo de levantamento de coleta de dados e a aplicação do jogo em questão.

Em nossos encontros semanais notamos que ocorria maior socialização entre eles, colaborando para o sucesso de cada dupla no transcorrer de COD.

Almeida (2005, p.72), enfatiza a importância da atividade coletiva. Desse modo, segundo ela, "o grupo que trabalha em colaboração é autor do processo de interação e criação onde cada membro é responsável pela própria aprendizagem e corresponsável pelo desenvolvimento do grupo".

\section{DISCUSSÃO}

Este trabalho procurou investigar através de pesquisa de campo a exploração de um jogo eletrônico que viesse a se constituir em um ambiente de aprendizagem lúdico-pedagógico e se o mesmo estimularia os sujeitos envolvidos a refletir sobe essa modalidade de exploração relacionando-o ao conteúdo ministrado pelos professores, em nosso caso, de Geografia e de História.

Optamos por um jogo de ação por encontrar nele as características necessárias como informações e técnicas complexas, rapidez de raciocínio e habilidade manual que devem ser desenvolvidas no decorrer do jogo, considerando que os jogos de computador exigem muito mais habilidades indutivas do que os jogos da era pré-computador. 
Os jogos eletrônicos constituem ambientes de desafios, pois exigem dos sujeitos uma avaliação das ações transcorridas durante as fases do jogo, resultando na construção do conhecimento.

Aprender a jogar é um processo contínuo de investigação, de construção de habilidades e de estratégias, de autoafirmação, em que o jogador vai conquistando terreno passo-a-passo frente ao software e frente aos demais jogadores, no caso de jogos de múltiplos participantes. Estes têm o fascínio adicional da interatividade real - você não joga só contra a máquina, mas contra pessoas reais, forma times, desenvolve estratégias coletivas.

A associação do game com atividades externas pode tornar o ambiente de sala de aula, ao mesmo tempo, divertido e poderoso em termos da aprendizagem dos alunos. O game pode levar o aluno a refletir, a buscar informações e, dessa forma, a construir e depurar seu conhecimento.

Outro campo de análise foi o de observar se o jogo eletrônico CALL OF DUTY criaria um ambiente de aprendizagem colaborativa.

Percebemos que os sujeitos interagiram entre si, trocando informações e alternando-se a frente do computador a cada fase do jogo. $O$ trabalho em equipe tende a apresentar melhores resultados, visto que um erro individual pode comprometer o sucesso do grupo. Logo todos passaram a compartilhar os desafios que COD apresentava a cada etapa.

\section{CONCLUSÃO}

A preocupação foi a de explorar um ambiente lúdico de aprendizagem através do trabalho cooperativo visando estimular os sujeitos nas aulas regulares.

$\mathrm{Na}$ avaliação, os jogos eletrônicos são perfeitamente aplicáveis na educação enquanto recurso pedagógico, auxiliando o professor em suas aulas, possibilitando um resultado satisfatório em relação à aprendizagem do conteúdo proposto.

É necessário, portanto, que se repense o uso do computador e outros recursos na escola, como também o processo de preparação para utilizar as tecnologias educacionais. Há de se considerar que as tecnologias educacionais, como qualquer outro recurso, são apenas um meio de atingir a aprendizagem, não um fim, e que cabe ao professor criar ambientes de aprendizagens adequados às necessidades e aos anseios dos alunos, garantindo-lhes uma educação que propicie autonomia e os tornem atores ativos do seu conhecimento. 


\section{REFERÊNCIAS}

ALMEIDA, M. E. B. Tecnologia na escola: criação de redes de conhecimentos. In: ALMEIDA, M. E. B; Moran, J. M. (Org). Integração das tecnologias educacionais. SEED, Brasília: MEC, 2005.]

ALVES, Lynn. Game Over - Jogos eletrônicos e violência. São Paulo: Editora Futura, 2005.

ARRUDA, Eucídio. Ciberprofessor - Novas tecnologias, ensino e trabalho. Belo Horizonte: Autêntica Editora, 2004.

BETTEGA, M. H. Educação continuada na era digital. São Paulo: Cortez editora, 2004.

SANTOS FILHO, J. C., GAMBOA, S. S. (Org.). Pesquisa educacional: quantidade-qualidade. 5a ed. São Paulo: Cortez editora, 1995.

GASPERETTI, Marco. O computador na educação. São Paulo: Esfera, 2001.

GREENFIELD, P. M. O desenvolvimento do raciocínio na era da eletrônica: os efeitos da TV, computadores e videogames. São Paulo: Summus Editorial, 1988.

HUIZINGA, Johan. Homo Ludens: o jogo como elemento da cultura. 5ạ edição. São Paulo: Perspectiva, 2005.

JOHNSON, Steven. Surpreendente! A televisão e o videogame nos tornam mais inteligentes. Rio de Janeiro: Editora Campus, 2005..

KENSKY, V. M. Educação e Tecnologias: O novo ritmo da informação. Campinas/SP: Papirus, 2007. O ensino e os recursos didáticos em uma sociedade cheia de tecnologias. In: VEIGA, IIma P. A. Didática: o ensino e suas relações. Campinas/SP: Papirus, 1996.

LÉVY, Pierre. O que é o virtual?. Tradução de Paulo Neves. São Paulo: ed. 34, 1996.

A inteligência coletiva - Por uma Antropologia do ciberespaço. Trad. de Luiz Paulo Rouanet. São Paulo: Loyola, 1998.

MENDES, C. L. Jogos eletrônicos: diversão, poder e subjetivação. São Paulo: Papirus, 2006.

MOITA, Filomena. Game on: jogos eletrônicos na escola e na vida da geração @. Campinas: Alínea, 2007. 